\title{
Health and Wealth in the United States and England- Two Very Different Countries With Similar Findings
}

Martin McKee, MD, DSc; David Stuckler, PhD

Although superficially they have much in common, health and social policy in the United States and England differ greatly. England provides universal health coverage; notwithstanding the achievements of the $\leftarrow$ Affordable Care Act, the Related article United States does not. England has retained strong social safety nets. Welfare in the United States is much less generous and, although those reaching 65 years can look forward to a range of benefits, support for the young is much less generous. But what do these differences mean for the health of those living in each country? Makaroun and colleagues ${ }^{1}$ ask this question in the accompanying article.

They are not the first to do so. We know that deaths from causes amenable to medical care are more frequent in the United States, which is unsurprising given problems with access to care in the American health care system. Health inequalities, at least as measured by income or education, also seem to be wider in the United States. ${ }^{2}$ However, Makaroun and colleagues ${ }^{1}$ add a new perspective, examining the role of wealth inequalities on health outcomes in the 2 countries. Their findings are both alarming and surprising.

First, they showed that the differences between those in the most and least wealthy quintiles were enormous; in the younger groups (aged between 54 and 65 years) those in the wealthiest quintile had 231 times as much value in assets as the least wealthy in the United States, whereas the gap was slightly narrower, at 180 times, in England. The corresponding figures were 163 times more in the United States and 115 times more in England among the older group (aged 66-76 years).

Second, they showed that greater wealth was consistently associated with improved health outcomes in both countries. In the younger sample, those in the least wealthy quintile were over 3 times as likely to die in the subsequent 10 years than those in wealthiest quintile. This difference narrowed slightly when adjusted for other factors, such as race, education, and sex, but, arguably, while the effect of adjustment is of interest to epidemiologists, it is the unadjusted figure that matters most for the individuals concerned. The difference in probability of dying between the most and least wealthy was slightly narrower among those aged between 66 and 76 years, but was still more than 2-fold. Similar findings were obtained when comparing patterns of disability.

What can we take from these findings? First, they remind us of the importance of addressing wealth inequalities. In the data sets used in the study, the degree of inequality of wealth was much greater than for income. Wealth inequalities had been narrowing during the first part of the 20th century but are now widening markedly across successive generations in England ${ }^{3}$ and between races in the United States. ${ }^{4}$
Second, although we already know that wealth inequalities have an impact on health, by showing similar health inequalities in quite different social and health care system contexts, this study adds considerably to what we already know about why wealth impacts health. Unsurprisingly, ownership of assets, especially those such as property that can generate unearned income, can insulate individuals against economic shocks. Yet this is only part of the story. Even without the prospect of unearned income, assets can be protective. A European study ${ }^{5}$ found that those facing problems paying rent experienced worsening health while those facing similar problems paying mortgages on properties they owned did not. And simply knowing that the value of one's assets has increased may benefit health. A British study ${ }^{6}$ found that home owners whose property increased in value during a property boom experienced better health and fewer chronic conditions than those whose property did not, findings attributed to resulting lower work intensity and healthier leisure choices.

Third, the empirical evidence presented here strengthens the case for policies on health inequalities that address the unequal distribution of wealth. These can be justified as a matter of fairness. Many of the most wealthy have become so not by their own efforts but by the play of chance, for example by owning assets in the right place at the right time or by inheriting wealth from family members.

Fourth, they confirm that, as with income and education, health varies over the entire range of wealth. This strengthens the case against welfare policies that only target the very poor rather than those that seek to help everyone while doing most for those lower down the wealth scale. This approach is termed progressive universalism and has the added benefit of convincing the middle classes that, although they may pay for the poor through their taxes, they also get something back. This reduces the tendency to view welfare as "us" paying for "them," which tends to undermine solidarity, especially when many of the recipients are identifiably different, for example because of skin color or dress.

Fifth, the finding that inequalities are similar in each country, despite their very different health and social systems, is very important. As noted by the authors, reaching age 65 years is a major milestone for Americans. An earlier comparison of the United States and England demonstrated how important it is for health outcomes, showing how death rates from many chronic disorders among Americans younger than 65 years were much higher than in England, but the gap narrowed after that age. In contrast, in England cancer survival declined at older ages, thought to reflect implicit age rationing in a cash limited system. ${ }^{7}$ In contrast, it remains high even at old age in the United States. The study by Makaroun and colleagues ${ }^{1}$ suggests that, despite these different systems, the impact on in- 
equalities in death and disability differ little, but the authors were unable to examine causes of death so it is possible that there could be differences in outcomes from particular conditions, as in the earlier study. ${ }^{7}$

It is also important to reflect on the major contribution that this study makes. It is one of the few to have examined inequalities in wealth and almost none have attempted international comparisons. This may seem surprising, given the now very extensive volume of research showing how the circumstances in which people are born, and in which they live, learn, and work have profound influences on their health. However, there is one very good reason why there are so few studies of wealth-related inequalities. Quite simply, it is ex- tremely difficult to obtain comparable data. That requires detailed questioning about matters that may be extremely sensitive. There may also be considerable challenges in valuing assets, such as homes, agricultural land, and pensions, with the figures varying over time, often for seemingly unrelated reasons. There are also challenges in reaching the very rich in surveys, a problem because of the highly skewed distribution of wealth. Finally, because wealth is often shared by all measures of a household or even extended family, there are questions about how to allocate wealth to individuals or to define units of analysis. Makaroun and colleagues ${ }^{1}$ were not able to overcome all these challenges, but they have gone far beyond earlier attempts and deserve congratulations for doing so.

\section{ARTICLE INFORMATION}

Author Affiliations: London School of Hygiene \& Tropical Medicine, London, England (McKee); Department of Policy Analysis and Public Management, Bocconi University, Milano, Italy (Stuckler).

Corresponding Author: Martin McKee, MD, DSc, Professor of European Public Health, London School of Hygiene \& Tropical Medicine, 15-17 Tavistock PI, London WC1H 9SH, England (martin .mckee@lshtm.ac.uk).

Published Online: October 23, 2017. doi:10.1001/jamainternmed.2017.5090

Conflict of Interest Disclosures: None reported.

\section{REFERENCES}

1. Makaroun R, Brown RT, Diaz-Ramirez LG, et al. Wealth-associated disparities in death and disability in the United States and England [published online October 23, 2017]. JAMA Intern Med. doi:10.1001 /jamainternmed.2017.3903

2. Banks J, Marmot M, Oldfield Z, Smith JP. Disease and disadvantage in the United States and in England. JAMA. 2006;295(17):2037-2045.

3. D'Arcy C, Gardiner L. The Generation of Wealth. London: Resolution Foundation \& Intergenerational Commission; 2017.

4. Shapiro T, Meschede T, Osoro S. The Roots of the Widening Racial Wealth Gap: Explaining the
Black-White Economic Divide. Pittsburgh, PA: Institute on Assets and Social Policy; 2013.

5. Clair A, Loopstra R, Reeves A, et al. The impact of housing payment problems on health status during economic recession: a comparative analysis of longitudinal EU SILC data of 27 European states, 2008-2010. SSM-population health. 2016;2:306-316.

6. Fichera E, Gathergood J. Do wealth shocks affect health? new evidence from the housing boom. Health Econ. 2016;25(suppl 2):57-69.

7. Desai M, Rachet B, Coleman MP, McKee M. Two countries divided by a common language: health systems in the UK and USA. J R Soc Med. 2010;103 (7):283-287. 